\title{
Cell proliferation and differentiation kinetics during spermatogenesis in Hydra carnea
}

\author{
Adelheid Munck and Charles N. David \\ Zoologisches Institut der Universität, Luisenstraße 14, D-8000 Munich 2, Federal Republic of Germany
}

Summary. Spermatogenesis in Hydra carnea was investigated. The cell proliferation and differentiation kinetics of intermediates in the spermatogenesis pathway were determined, using quantitative determinations of cell abundance, pulse and continuous labelling with ${ }^{3} \mathrm{H}$-thymidine and nuclear DNA measurements. Testes develop in the ectoderm of male hydra as a result of interstitial cell proliferation. Gonial stem cells and proliferating spermatogonia have cell cycles of $28 \mathrm{~h}$ and $22 \mathrm{~h}$, respectively. Stem cells undergo four, five or six cell divisions prior to meiosis which includes a premeiotic $\mathrm{S}+\mathrm{G} 2$ phase of $20 \mathrm{~h}$ followed by a long meiotic prophase $(22 \mathrm{~h})$.

Spermatid differentiation requires $12-29 \mathrm{~h}$. When they first appear, testes contain only proliferating spermatogonia; meiotic and postmeiotic cells appear after 2 and 3 days, respectively and release of mature sperm begins after 4 days. Mature testes produce about 27,000 sperm per day over a period of 4-6 days: about 220 gonial stem cells per testis are required to support this level of sperm differentiation. Further results indicate that somatic (e.g. nematocyte) differentiation does not occur in testes although it continues normally in ectodermal tissue outside testes. Our results support the hypothesis that spermatogenesis is controlled locally in regions of the ectoderm where testes develop.

Key words: Hydra carnea - Spermatogenesis - Cell cycle kinetics - Stem cells - Sexual differentiation

\section{Introduction}

Germ cell formation and sexual reproduction have been described morphologically in a variety of hydra species (Kleinenberg 1872; Weismann 1883; Brauer 1891; Downing 1905; Brien and Reniers-Decoen 1950, 1951; Brien 1965; Zihler 1972). In the following report, we present a quantitative analysis of spermatogenesis in Hydra carnea. The purpose of the present experiments was to determine the kinetic parameters of the steps in spermatogenesis from stem cells to differentiated sperm and we also wished to obtain quantitative estimates of stem cell requirements for spermatogenesis as well as of the partitioning of stem cells between germline and somatic differentiation in sexual hydra.

Gametes of both sexes in hydrozoans are derived from interstitial cells (see Tardent 1978 for review). In vegetative

Offprint requests to: Adelheid Munck at the above address animals these cells are the precursors of nerve cells and nematocytes (see Bode and David 1978 for review). At present it is not known whether one stem cell population can differentiate into both somatic and germline cells. However, two distinct stem cell populations have recently been observed in Hydra oligactis (Littlefield et al. 1984): one which stains with a sperm-specific monoclonal antibody and one which does not.

Hydra carnea were used for the present experiments because in laboratory cultures a significant proportion of animals undergo continual sexual differentiation. Although $H$. carnea has been described as hermaphroditic (Hyman 1931), the behaviour of laboratory cultures is better described as unstably gonochoristic. This species belongs to a group of hydra (e.g. H. attenuata; Tardent 1966) in which both somatic and germline differentiation occur in parallel. However, as our results indicate, somatic and germline differentiation are restricted to particular regions of the body column.

\section{Materials and methods}

Animals. Male Hydra carnea were used for all experiments. A significant proportion of these animals produce gametes continuously under laboratory conditions. They were kept in mass cultures in plastic dishes $(20 \times 20 \times 5 \mathrm{~cm})$ with 500-1,000 animals per 0.751 culture medium according to the method of Loomis and Lenhoff (1956). The culture medium was prepared from deionized water containing $1 \mathrm{mM} \mathrm{CaCl}_{2}, \quad 0.1 \mathrm{mM} \mathrm{MgCl}_{2}, \quad 0.1 \mathrm{mM} \mathrm{KCl}$ and $1 \mathrm{mM} \mathrm{NaHCO}, \mathrm{pH} 7.8-8.0$, at $18^{\circ} \mathrm{C}$. Animals were fed daily with newly hatched Artemia sp. and washed $6 \mathrm{~h}$ after feeding.

Maceration and cell preparations. Whole animals were macerated according to the method of David (1973). After adding $50 \mu 1$ maceration solution (acetic acid: glycerin:water; $1: 1: 13$ ) per animal, the maceration vial (vol. ca. $2 \mathrm{ml}$ ) was incubated at $38^{\circ} \mathrm{C}$ for $15 \mathrm{~min}$. The tissue was dissociated into single cells or cell clusters by gently shaking the vial and the cells were fixed by adding $50 \mu 18 \%$ formaldehyde.

The same method was used to macerate testes (including the underlying tissue), which were excised from the body column with a scalpel. One to seven testes were macerated together using $10 \mu 1$ maceration solution and formaldehyde per testis. 
Gamete precursors occur as clusters of cells (nests) in macerations. Ideally such clusters contain $2^{n}$ cells. However, due to breakage during macerations, clusters with intermediate cell numbers also occur. In the case of big interstitial cells nest breakage was not extensive (see Fig. 2) and "broken" nests were assumed to represent the next highest geometrical number. However, due to extensive nest breakage, little interstitial cells and meiotic cells were scored only as total cells. Nests are referred to by the number of cells they contain: $1 \mathrm{~s}, 2 \mathrm{~s}, 4 \mathrm{~s}, 8 \mathrm{~s}$ etc.

${ }^{3} \mathrm{H}$-thymidine labelling and autoradiography. Animals were labelled with $\mathrm{Me}^{3} \mathrm{H}$-thymidine (Amersham Buchler, Braunschweig, FRG; $44 \mathrm{Ci} / \mathrm{mM}$ ) by injecting ca. $0.5 \mu \mathrm{l}$ $(100 \mu \mathrm{Ci} / \mathrm{ml})$ into the gastric cavity as described by David and Campbell (1972). For pulse labelling the animals were macerated for about $40 \mathrm{~min}$ after injection. Continuous labelling was achieved by injecting ${ }^{3} \mathrm{H}$-thymidine repeatedly at intervals of less than $12 \mathrm{~h}$. Labelled cells were identified by autoradiography using Kodak NTB-2 emulsion (exposed for 7 days at $4^{\circ} \mathrm{C}$ ). Cell types which were difficult to identify after autoradiography were identified and mapped in macerations before the slides were covered with film.

Staining. To identify chromosomes in meiotic nuclei, macerations were stained with Feulgen according to Romeis (1968). Nests of differentiating nematocytes were specifically stained with thiolacetic acid-lead nitrate according to David and Challoner (1974).

Nuclear DNA determination. Cell preparations were stained with the DNA-specific fluorescent dye, Hoechst 33258 , which binds to DNA independent of the state of chromatin condensation (Cowden and Curtis 1981). Slides with cells were washed and incubated in staining solution $(1 \mu \mathrm{g} / \mathrm{ml}$ Hoechst in $2 \mathrm{M} \mathrm{NaCl}, 2 \mathrm{mM}$ EDTA, $200 \mathrm{mM} \mathrm{Na}_{2} \mathrm{HPO}_{4}$, pH 7.4) for $0.5 \mathrm{~min}$, washed again and measured in a Leitz Dialux 20 fluorescence microscope equipped with a photometer (Leitz MPV compact).

Nerve cells were used as a standard for diploid $(2 n)$ DNA values (David and Gierer 1974). The error in individual determination is about $\pm 25 \%$. This leads to relatively broad distributions for cells in the same cell cycle positions, e.g. sperm, nerve cells of meiotic cells (see Fig. 3).

Release of sperm. Single sexually active hydra were placed in $150 \mu 1$ culture medium in Eppendorf tubes. After varying intervals the animals were transferred to a new tube and the released sperm were fixed with $20 \mu$ formaldehyde and counted.

\section{Results}

\section{Formation of testes}

In a sexually active $H$. carnea, formation of a new testis can be seen as a local swelling of the ectoderm located in most cases in the upper region of the body column. Within 3-4 days the swelling develops into a mature testis with a nipple on its tip. A sexually mature animal has about three to eight testes simultaneously. Individual testes persist for about 10 days.

A mature testis is covered by ectodermal cells of the body column. These cells are stretched apically to make room for the mass of proliferating and differentiating cells of the spermatogenesis pathway, which distend the interstitial spaces normally occupied by interstitial cells (Brien 1961). The periphery of the testis is relatively transparent and appears to be filled with liquid. On the outer tip of the testis there is a nipple in which actively swimming sperm can be seen. Sperm are released from the nipple at irregular intervals.

\section{Cell composition of mature testes}

In order to characterize their cells, mature testes were excised from the body column and macerated. The macerations were then examined by phase-contrast microscopy. All stages in the differentiation pathway from gonial stem cells to mature sperm are represented in such preparations. In the following description we have attempted to identify the types of cells seen in macerations with the various stages in the differentiation pathway.

Gonial stem cells. Nests of one and two big interstitial cells $(1 s+2 s)$ occur in large numbers in testes. These cells have a large nucleus, with one to three conspicuous nucleoli and uniform, granular cytoplasm (Fig. 1a). Because of their morphological similarity to somatic stem cells in asexual hydra (David 1973; David and Gierer 1974), these cells have been identified as the gonial stem cells.

Proliferating spermatogonia (big). In addition to gonial stem cells testes contain nests of $4,8,16$ and 32 big interstitial cells (Fig. 1 b). These cells are morphologically similar to the gonial stem cells. However, because they occur in larger nests they appear to be derived from stem cells by a series of synchronous cell divisions.

Proliferating spermatogonia (little). Testes contain numerous clusters of little interstitial cells (Fig. 1c). The clusters range in size from a few cells up to 60 or more. Little interstitial cells are morphologically distinct from big interstitial cells: they are rounder and smaller; their nuclei appear darker in phase-contrast microscopy and contain no visible nucleoli. They have only a small peripheral zone of cytoplasm around the nucleus and many of them have flagellae.

Cells in meiotic prophase. Testes contain a second type of little interstitial cell (Fig. $1 \mathrm{~d}$ ). These cells also have flagellae and occur in clusters which range in size from a few cells up to 60 or more. These cells, however, have a markedly altered nuclear morphology; the nuclear material appears condensed and is surrounded by a clear zone which is bright in phase-contrast microscopy. The nucleus does not contain a visible nucleolus. Based on their nuclear morphology, it appeared likely that these cells were in meiotic prophase. This was confirmed in Feulgen-stained preparations, in which the condensed chromatin of the nucleus was clearly visible.

The subsequent stages of meiosis appear to be quite short, since such cells are infrequent in macerations. During these meiotic stages flagellae disappear. Figure $1 \mathrm{e}$ shows an anaphase II.

Postmeiotic spermatids. Mature testes contain large numbers of differentiating spermatids (Fig. 1e) and mature 

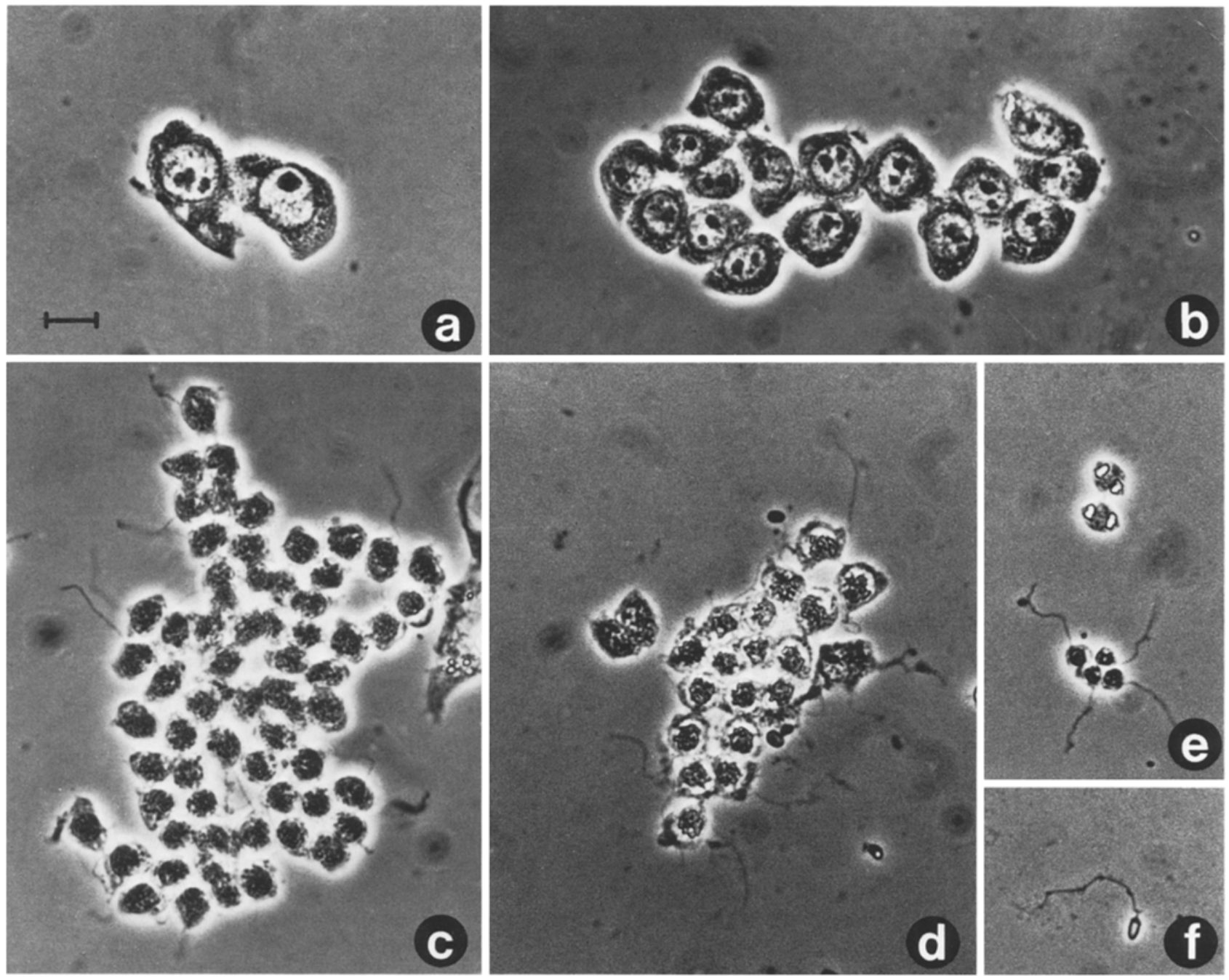

Fig. 1 a-f. Gonial cells in maceration preparations: a gonial stem cells; $\mathbf{b}$ nest of big interstitial cells; $\mathbf{c}$ nest of little interstitial cells; d nest of meiotic cells; e group of four postmeiotic spermatids and two spermatocytes in anaphase II; f mature motile sperm. Bar $10 \mu \mathrm{m}$

sperm (Fig. 1f). It appears that nests of cells in meiotic prophase dissociate to give single cells during the later phases of meiosis. However, the division products of single meiotic cells remain attached and thus differentiating spermatids occur frequently in groups of four cells. They have flagellae and a condensed nucleus surrounded by a clear halo of cytoplasm. During differentiation to mature sperm, the nucleus undergoes further condensation and the cytoplasm disappears.

Big and little interstitial cells as well as meiotic cells are mainly present in clusters. Whereas the cluster sizes of little interstitial cells and meiotic cells show a broad variation - probably as a consequence of breakage during the maceration procedure - the nests of big interstitial cells occur frequently in sizes of $2^{n}$ cells. Figure 2 shows the distribution of nest sizes of big interstitial cells. There are clear peaks in the distribution at 4 and 8 cells per nest. A smaller peak appears to be present at 16 cells per nest. In addition, there are nests of irregular size up to 32 cells, suggesting that 32 is probably the maximum size of big interstitial cell nests. It appears likely that the irregularly sized nests are the result of breakage of nests which originally contained $2^{\mathrm{n}}$ cells.

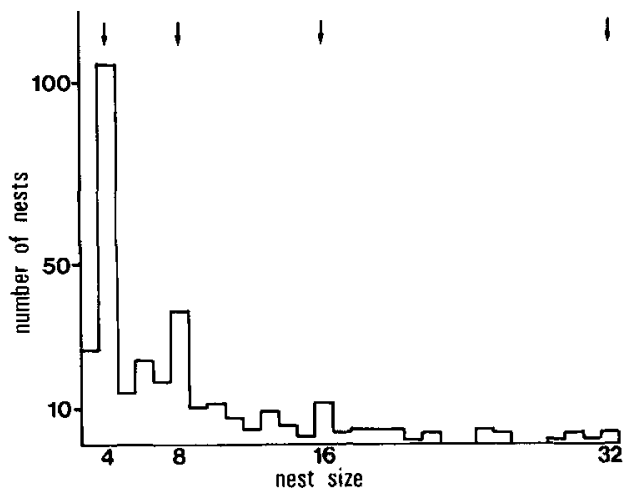

Fig. 2. Nest size distribution of big interstitial cells in preparations of macerated testes. A total of 315 nests were scored in four animals. The arrows indicate values of $2^{\text {n }}$

\section{Determination of nuclear DNA content of cells in testes}

In order to characterize further the different cell types in testes, the nuclear DNA content of individual cells of each cell type was measured. Cell macerations of testes were stained with the DNA-specific fluorescent dye, Hoechst 


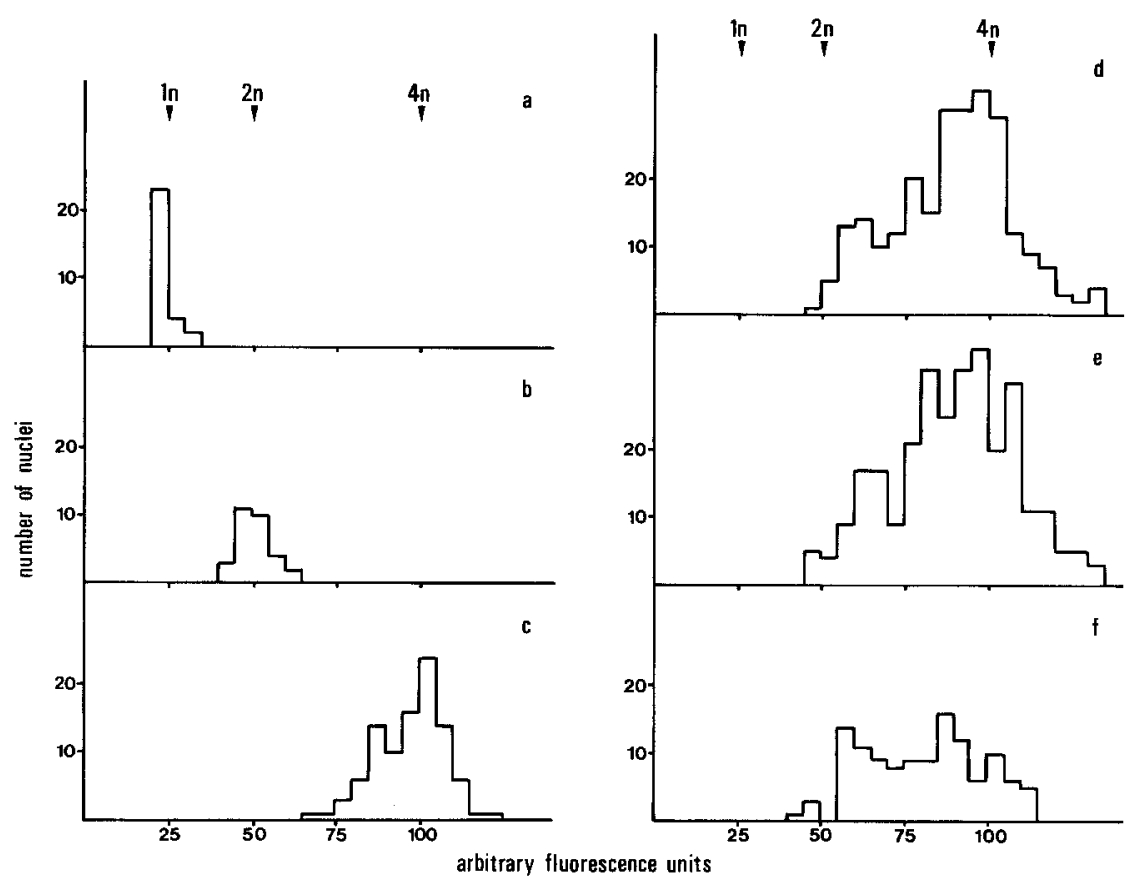

Fig. 3a-f. Distribution of nuclear DNA contents in different cell types in testes. One cell/nest was measured; all cells in a single nest contain the same amount of DNA. DNA values are given in arbitrary units of fluorescence. a sperm (1n); b nerve cells $(2 n)$; c cells in meiotic prophase $(4 \mathrm{n})$; $\mathbf{d}$ big interstitial cells $(1 \mathrm{~s}+2 \mathrm{~s})$; e big interstitial cells $(4 \mathrm{~s}-32 \mathrm{~s}) ; \mathbf{f}$ little interstitial cells
33258 , and the nuclear DNA content of single cells determined microfluorometrically. The distribution of nuclear DNA contents for each cell type is shown in Fig. 3. The DNA content of differentiated nerve cells (Fig. $3 \mathrm{~b}$ ) was used as a standard for the diploid (2n) DNA content of nuclei (David and Campbell 1972). As expected postmeiotic spermatids and sperm contain In DNA levels relative to the $2 \mathrm{n}$ standard (Fig. $3 \mathrm{a}$ ). Cells in meiotic prophase have 4 n nuclear DNA contents (Fig. 3c). By comparison, nests of 1 and 2 big interstitial cells (Fig. 3d), nests of 4-32 big interstitial cells (Fig. 3e) and nests of little interstitial cells (Fig. $3 \mathrm{f}$ ) have nuclear DNA contents which range from $2 \mathrm{n}$ to $4 \mathrm{n}$. This indicates that these cells are primarily in the $\mathrm{S}$ phase of the cell cycle and are therefore proliferating. In addition to cells with S-phase DNA contents, big interstitial cells also appear to have some cells with G2 DNA values, suggesting that these cells also have a significant $\mathrm{G} 2$ phase in their cell cycle.

\section{Temporal appearance of spermatogonia, meiotic cells and differentiating spermatids in developing testes}

By macerating testes of known developmental age, it is possible to observe the sequential appearance of proliferating spermatogonia, meiotic cells and differentiating spermatids. Such observations reveal in a qualitative way the kinetics of spermatogenesis. Figure 4 shows the results of such observations on a series of individual animals. Although there is considerable variation in the absolute levels of each cell type between individual animals, the sequential appearance of spermatogonia, meiotic cells and differentiating spermatids is remarkably consistent.

In Fig. 5 the kinetics of appearance of each cell type is shown. Since it is not possible to locate the site of testis differentiation prior to its appearance as a swelling on the surface of the body column, the earliest developmental stage which can be examined is already 1 day old. Such very young testes contain mainly big interstitial cells in nest sizes ranging from 1 to 32 and also little interstitial cells in large clusters. The number of big interstitial cells decreases about two-fold during the first 2 days of testis development and then remains roughly constant. The number of little interstitial cells is relatively low on day 1 and rises to about 10,000 cells per testis on day 4. Meiotic cells are not found before the second day and increase to $5,000-7,000$ cells by day 4. Postmeiotic cells first appear in testes on day 3 and reach a level of about 30,000 cells per testis between days 4 and 6 . By day 10, the levels of all cell types have declined.

The results shown in Fig. 5 indicate a delay of about 1.7 days between the appearance of little interstitial cells and meiotic cells, suggesting that this stage of spermatogenesis may include more than one cell cycle (see below). From meiotic cells to postmeiotic cells there is a delay of about 1 day, indicating that the duration of meiosis is about 1 day.

Beginning on day 4 mature sperm are released at more or less regular time intervals. Measurements of the number of sperm released yielded values of $700-1,200 \mathrm{sperm} / \mathrm{h}$ with no marked variation during the course of a day (data not shown). This level of sperm production is maintained for 46 days in mature testes. Hence mature testes must contain sufficient numbers of precursors in the spermatogenesis pathway to support this rate of sperm production.

\section{Pulse and continuous labelling with ${ }^{3} H$-thymidine}

Labelling with ${ }^{3} \mathrm{H}$-thymidine was used to estimate the duration of the cell cycle of proliferating spermatogonia as well as the kinetics of meiosis and postmeiotic differentiation. Animals bearing mature testes were pulse or continuously labelled for varying times and then testes were excised, macerated and autoradiographed. The labelling indices of the various cell types are shown in Fig. 6 .

Pulse labelling (a single injection of ${ }^{3} \mathrm{H}$-thymidine given at $t_{\mathrm{o}}$ ) identified big and little interstitial cells as proliferating cell populations (Fig. 6A-E). By comparison, meiotic cells and differentiating spermatids (Fig. 6F, G) are not labelled in a ${ }^{3} \mathrm{H}$-thymidine pulse but become labelled at later times due to differentiation from labelled precursors. 

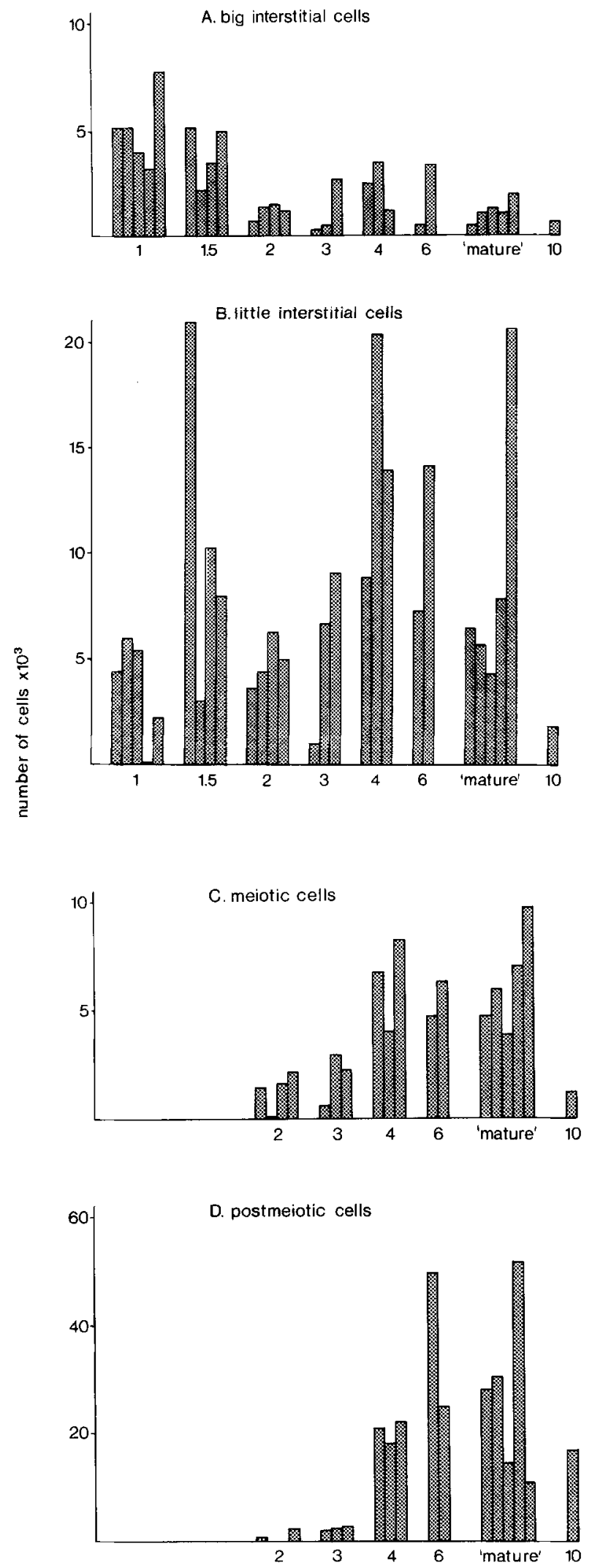

age of testes, days

Fig. 4. Numbers of big interstitial cells $(A)$, little interstitial cells $(B)$, meiotic cells $(C)$ and postmeiotic cells $(D)$ in testes of different developmental age. Each $b$ ar represents the results from an individual sexual animal having three to eight testes. The results are given as the average cell number per testis. "Mature" testes were defined morphologically; they were probably $4-8$ days old

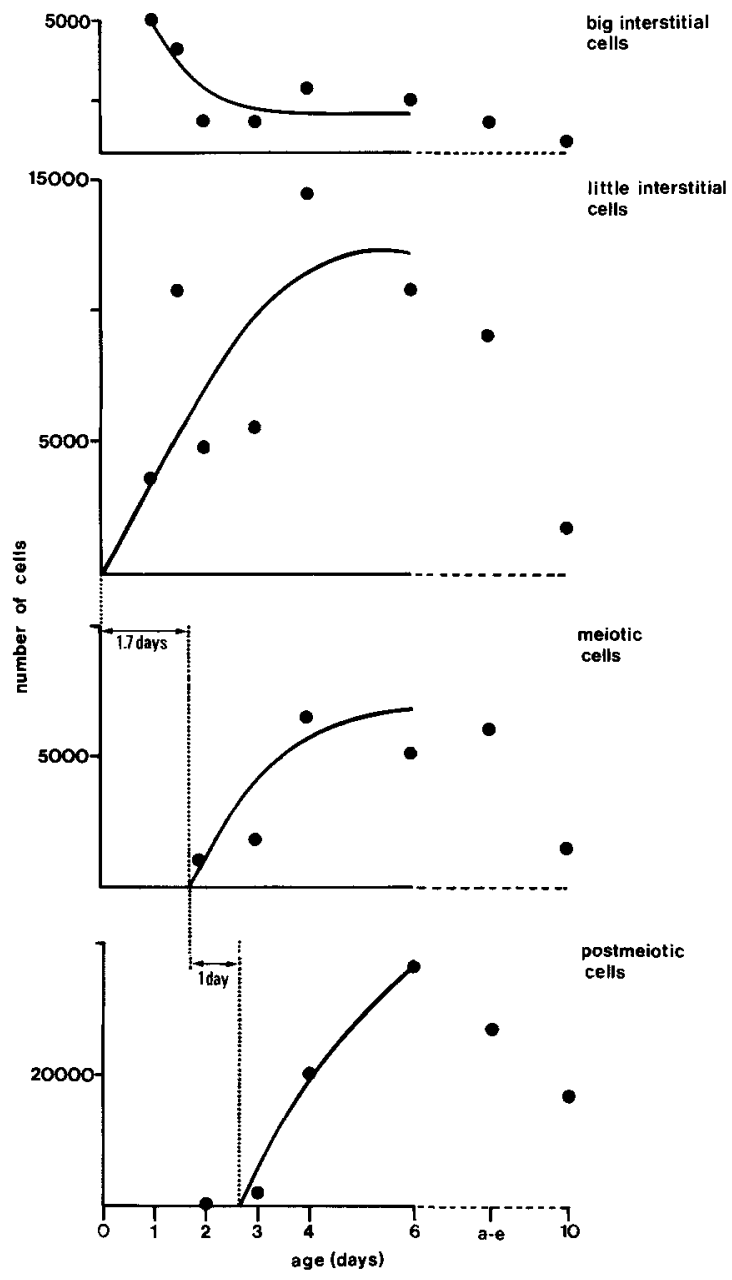

Fig. 5. The kinetics of appearance of big interstitial cells, little interstitial cells, meiotic cells and postmeiotic cells during development of testes. The values represent the means for each cell type at each age class from the data in Fig. 4. The lines indicate the trends in the data points

Proliferating cell populations. Nests of 1 and 2 big interstitial cells are $45 \%$ labelled immediately following pulse labelling. The population is $100 \%$ labelled after about $16 \mathrm{~h}$ under continuous labelling conditions. Thus these cells exhibit labelling kinetics similar to those of somatic stem cells in asexual hydra (Campbell and David 1974). By comparison, nests of 4-32 big interstitial cells are completely labelled after about $8 \mathrm{~h}$, suggesting that they have a shorter cell cycle than gonial stem cells (see Discussion). While scoring little interstitial cells in autoradiograms, it became clear that the labelling properties of these cells varied with nest size. In general, large nests had higher labelling indices than small nests. In order to quantify this difference, we classified nests according to their size: "small" (5-20 cells), "medium" (20-40 cells) and "large" (more than 40 cells). Although there is considerable scatter in the experimental points due to variability between individual animals and due to breakage of larger nests to yield smaller nests, there are clear trends in the results (Fig. 6C-E). First, the level of pulse labelling increases with increasing nest size. "Small" nests are 50\% pulse labelled, "medium" nests are about $70 \%$ pulse labelled, while "large" nests are about 

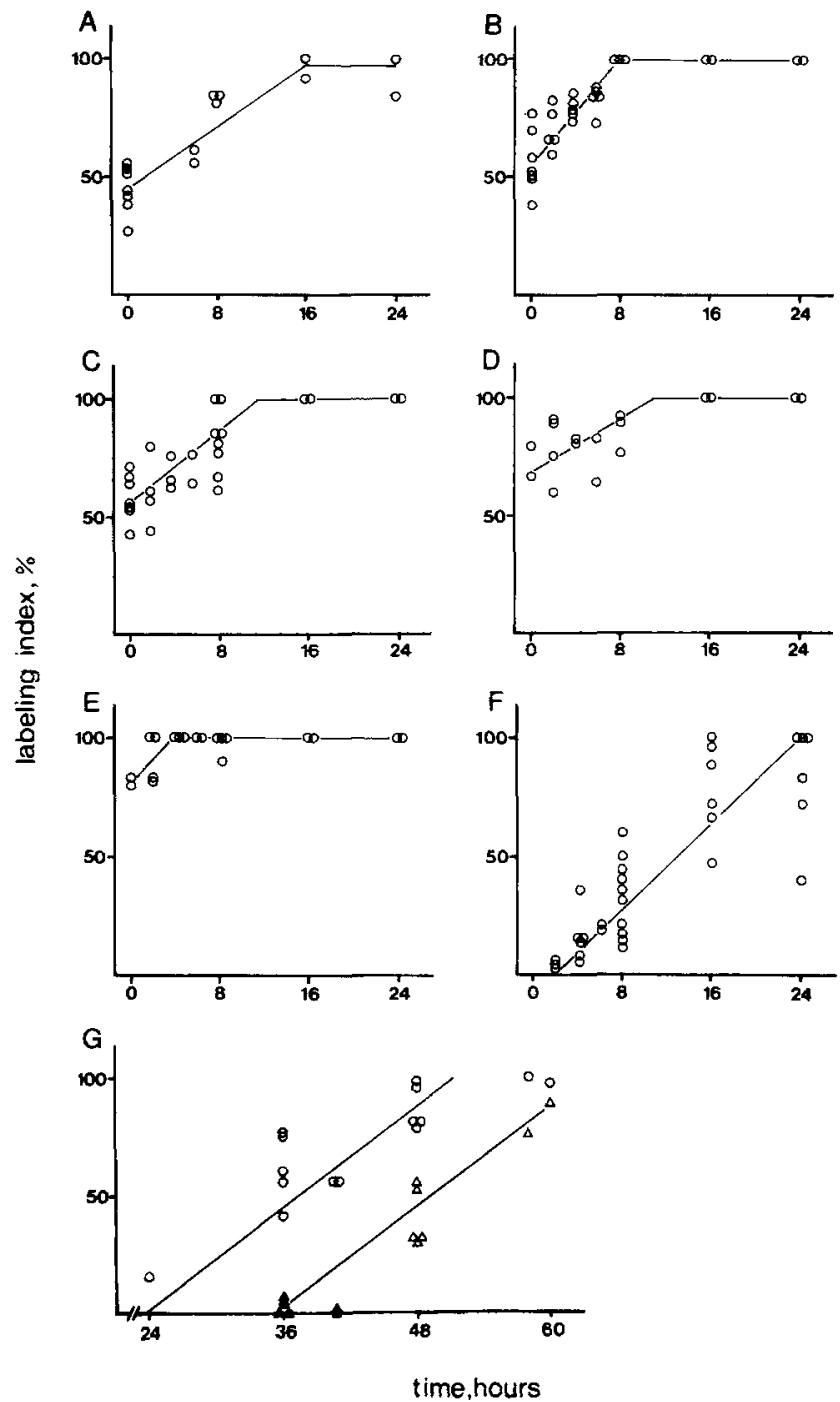

Fig. 6A-G. Kinetics of ${ }^{3} \mathrm{H}$-thymidine labelling of different cell types: $\mathbf{A}$ big interstitial cells (1s $+2 \mathrm{~s}$ ); $\mathbf{B}$ nests of 4-32 big interstitial cells; $\mathbf{C}$ nests of 5-20 little interstitial cells; D nests of $20-40$ little interstitial cells; E nests of more than 40 little interstitial cells; F meiotic cells; $\mathbf{G}$ spermatids (o) and sperm $(\Delta)$. Each data point represents the labelling index in a single animal with several testes. The lines indicate the trend in the data points

$85 \%$ pulse labelled. Second, the time required to achieve $100 \%$ labelling also varies with nest size: "small" and "medium" nests require about $8-12 \mathrm{~h}$ to complete labelling, while "large" nests are completely labelled after only $2-3 \mathrm{~h}$. Together these results suggest that, with increasing nest size, the $S$ phase occupies a larger proportion of the cell cycle. This complex pattern of labelling kinetics suggests that little interstitial cells are composed of different populations of cells. Some of these cells are proliferating precursors, while others are cells in the premeiotic S phase (see Discussion).

Meiotic cells. As expected, cells in meiosis are not pulse labelled (Fig. 6F). The first labelled meiotic cells appear $2 \mathrm{~h}$ after the onset of ${ }^{3} \mathrm{H}$-thymidine labelling suggesting a brief delay between the end of the premeiotic $S$ phase and meiotic prophase. The population of meiotic cells is completely labelled by $24 \mathrm{~h}$ after the onset of ${ }^{3} \mathrm{H}$-thymidine labelling. Hence meiosis appears to last about $22 \mathrm{~h}$.
Spermatid differentiation. Figure $6 \mathrm{G}$ indicates that labelled precursors begin to appear in the population of differentiating spermatids at $24 \mathrm{~h}$, which is also the time at which the meiotic population becomes fully labelled. The population of spermatids achieves $100 \%$ labelling at about $53 \mathrm{~h}$, indicating that the duration of spermatid differentiation is maximally $29 \mathrm{~h}$. However, the occurrence of labelled sperm beginning at $36 \mathrm{~h}$ indicates that spermatid differentiation can occur in some cases in as little as $12 \mathrm{~h}$. Since these results were obtained on preparations which contained several testes from a single animal, it is not clear whether the variability in the duration of spermiogenesis occurs between cells within a single testis or between individual testes.

\section{Distribution of differentiating nematocytes in sexual hydra}

Differentiating nematocytes can be specifically stained with thiolacetic acid-lead nitrate during a brief period at the end of capsule differentiation while the cells are still present as nests in the body column (David and Challoner 1974). Since the background tissue is unstained, whole mounts of hydra can be easily scanned for the presence of differentiating nematocytes. In asexual animals differentiating nematocytes are uniformly distributed throughout the body column but absent from the hypostome and basal disc as well as the immediately adjacent tissue.

Since spermatogenesis appears to be localized in testes and seems to exclude other kinds of differentiation from these areas (see Discussion), it was of interest to determine the occurrence and localization of nematocyte differentiation in sexual animals. A number of hydra with testes were stained for differentiating nematocytes with thiolacetic acidlead nitrate. Differentiating nematocytes were abundant throughout the gastric region of such animals but were never observed in testes. Figure 7 shows part of the body column, including the testis, of one such animal. The nematocytes appear as clusters of darkly stained capsules in the otherwise unstained tissue. Nests of differentiating nematocytes are fairly uniformly distributed in the gastric tissue but are clearly absent from the testis itself. The animal shown in Fig. 7 is particularly interesting because, in addition to the absence of differentiating nematocytes from the testis itself, there is a region to the left of the testis which is also clear of nematocytes. This clear area appears to be a site of future testis differentiation. If this interpretation is correct, it implies that a local inhibition of nematocyte differentiation occurs before overt testis differentiation.

\section{Discussion}

\section{Cell types and a model for spermatogenesis}

From the results presented here it is possible to deduce the steps involved in the spermatogenesis pathway. In Fig. 8 the differentiation pathway is shown schematically. The pathway begins with gonial stem cells, which give rise by a series of synchronous cell divisions to nests of big interstitial cells (only nests of four and eight big interstitial cells are shown in Fig. 8). Following another round of cell division, nests of little interstitial cells arise. These cells complete one further round of proliferation to create nests of premeiotic cells, which undergo a premeiotic $S$ phase fol- 


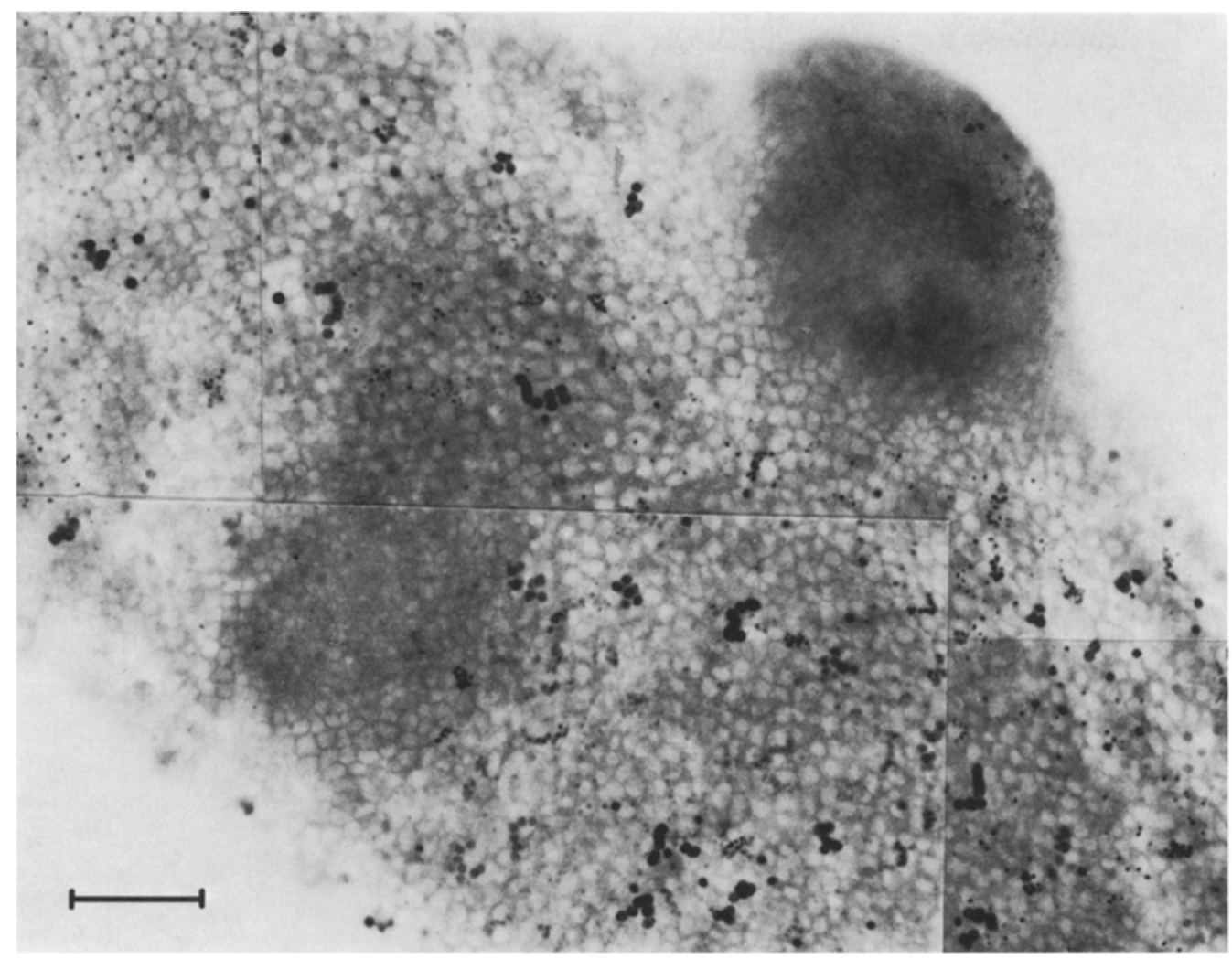

Fig. 7. Distribution of differentiating nematocytes in the gastric region of a sexual hydra. The nematocytes appear as clusters of darkly staining capsules in the ectoderm. The hypostome is to the upper left. A nearly mature testis is located on the upper side of the animal. Below it there is an area free of nematocytes that appears to be a developing testis. Stained with thiolacetic acid-lead nitrate. Bar $100 \mu \mathrm{m}$

lowed by meiosis. The postmeiotic daughter cells then differentiate into sperm. These observations are in good agreement with those of Littlefield et al. (1984) for H. oligactis.

There are several notable features of the spermatogenesis pathway shown in Fig. 8. While most of the proliferation steps occur as big interstitial cells, there is one further round of cell division as little interstitial cells before spermatogonia enter the premeiotic S phase. Hence there are two classes of little interstitial cells: those in the cell division cycle and those in premeiotic $\mathrm{S}$ phase. Although proliferating little interstitial cells can not be distinguished morphologically from cells in premeiotic $S$ phase, their existence can be deduced from two lines of evidence. First, the results in Fig. 5 indicate a 1.7-day delay between the appearance of little interstitial cells and meiotic cells during testis differentiation. This is the expected delay assuming one cell division cycle (about $22 \mathrm{~h}$ ) and premeiotic $\mathrm{S}+\mathrm{G} 2$ phase $(20 \mathrm{~h})$ (see below). Second, the large number of little interstitial cells present in testes can only be accounted for by assuming that these cells undergo a cell division cycle prior to premeiotic $\mathrm{S}$ phase. If big interstitial cells divided and gave rise directly to cells in premeiotic $S$ phase, one would expect one-third fewer little interstitial cells than are observed in testes (see below).

A second feature of the spermatogenesis pathway deserves comment. Our results indicate that the number of cell divisions between the stem cell stage and meiosis is not fixed, i.e. not all stem cells proceed through four cell divisions and undergo meiosis as nests of 32 cells as shown in Fig. 8. Instead it appears that stem cells can undergo four, five or six cell divisions prior to meiosis. The principal evidence for this comes from the unequal numbers of nests of $4,8,16$ and 32 big interstitial cells (Table 1, line 6a). Were these nests part of a linear sequence in which all stem cells divided a fixed number of times before meiosis, one would expect roughly equal numbers of each nest class since the cell cycle duration of each class appears to be the same (see below). The results shown in Table 1, line $6 \mathrm{a}$ indicate that this is not the case: the frequency of nests decreases with increasing nest size. As discussed below, the size distribution is most compatible with a model in which stem cells undergo four, five or six cell divisions prior to meiosis.

The timing of spermatogenesis appears to be correlated with the appearance of testes. Prior to testis formation only big interstitial cells are present. Then coincident with the appearance of testes, big interstitial cells divide to give nests of little interstitial cells (Fig. 5). Littlefield et al. (1984) have made a similar observation in $H$. oligactis and were able to show that the transition to little interstitial cells occurred locally in the developing testis. Hence there appears to be a signal controlling proliferation of sperm precursors which is restricted to the region of the testis (see below).

\section{Cell cycle of proliferating spermatogonia and the kinetics of meiosis and sperm differentiation}

The cell cycle parameters of proliferating spermatogonia can be estimated from the nuclear DNA distributions 


\section{proliferation of precursors}

\section{premeiotic S meiosis spermiogenesis}

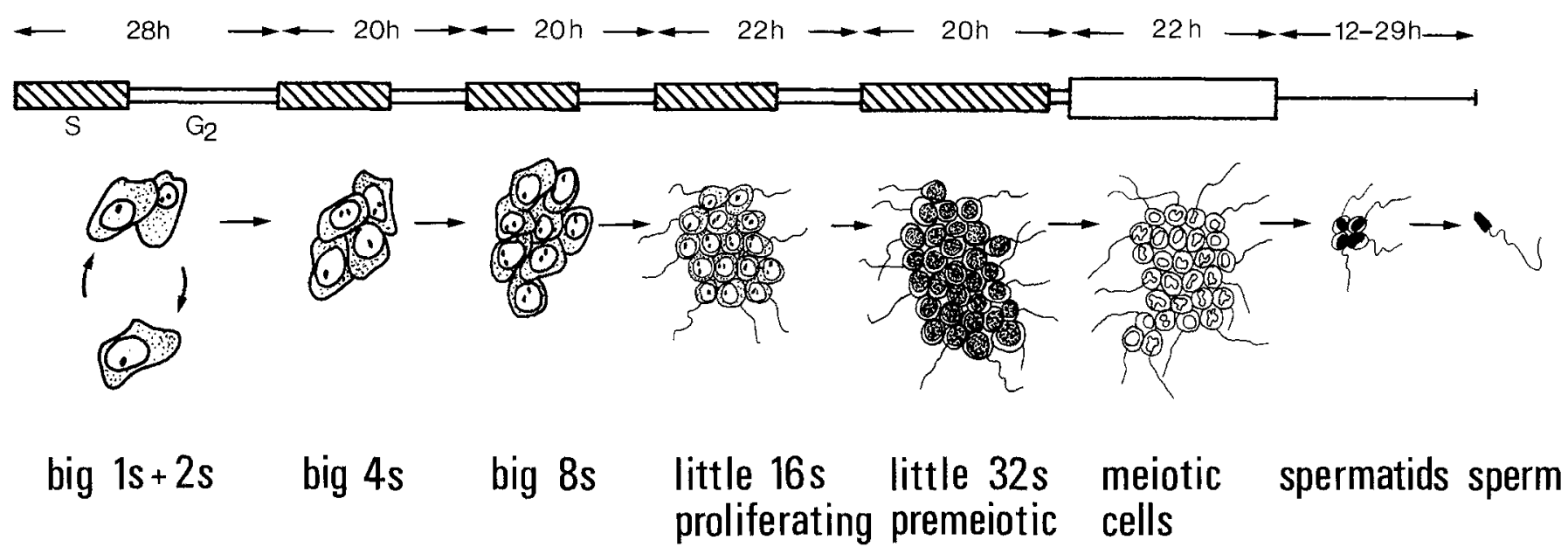

Fig. 8. Schematic representation of the spermatogenesis pathway from gonial stem cells to mature sperm. The duration of the individual phases is given in hours

(Fig. 3) and the ${ }^{3} \mathrm{H}$-thymidine-labelling kinetics (Fig. 6). The nuclear DNA distributions indicate that big and little interstitial cells in testes have DNA contents between $2 \mathrm{n}$ and $4 n$, which is characteristic of proliferating cells in the $\mathrm{S}$ phase. There is no evidence of a peak of cells with $\mathrm{Gl}$ DNA content, suggesting that spermatogonia, like proliferating interstitial cells in asexual $H$. attenuata (Campbell and David 1974), do not have a Gl phase. Little interstitial cells also show no evidence of a peak of cells with G2 DNA content, suggesting that this phase is short or absent. Big interstitial cells, however, do show a peak in the DNA distribution at $4 n$, indicating that these cells have a G2 phase.

From the ${ }^{3} \mathrm{H}$-thymidine-labelling data in Fig. 6 , it is possible to estimate the duration of the cell cycle for proliferating spermatogonia. Nests of 1 and 2 big interstitial cells are $45 \%$ labelled in a pulse and thus $45 \%$ of the cell cycle is $\mathrm{S}$ phase. Since the remaining $55 \%$ of the population is labelled by $16 \mathrm{~h}$, the entire cycle is about $28 \mathrm{~h}$. A similar calculation for nests of 4-32 big interstitial cells leads to a cell cycle of about $20 \mathrm{~h}$.

Calculation of the cell cycle parameters of little interstitial cells is more complicated, since these cells are a mixed population of cells in a division cycle and cells in premeiotic S phase (Fig. 8). It is reasonable to assume that "large" nests (see Results) consist primarily of cells in premeiotic $S$ phase rather than the division cycle, since these nests are similar in size to nests of meiotic cells. About $85 \%$ of these cells are labelled in a pulse (Fig. 6E) and hence $S$ phase occupies almost the entire time between mitosis and meiotic prophase. The remaining $15 \%$ of these cells become labelled after $3 \mathrm{~h}$, indicating that the delay between the end of premeiotic $S$ phase and meiotic prophase is about $3 \mathrm{~h}$ (see also Fig. $6 F$ ). Hence the duration of the premeiotic $S+G 2$ phase is about $20 \mathrm{~h}$.

The cell cycle kinetics of little interstitial cells in the division cycle can be similarly estimated by assuming that most "small" nests (see Results) of interstitial cells are in the division cycle rather than in premeiotic $S$ phase. These cells exhibit labelling kinetics (Fig. 6C) which are very similar to nests of 4-32 big interstitial cells (Fig. 6B): the pulse- labelling index is about $55 \%$ and $10-12 \mathrm{~h}$ are required to achieve $100 \%$ labelling. This leads to an estimated cell cycle of $20-24 \mathrm{~h}$.

From the above discussion and further results on the duration of meiosis and postmeiotic differentiation (Fig. 6F, G) it is possible to summarize the temporal sequence of events during spermatogenesis (see Fig. 8). Gonial stem cells (nests of one and two big interstitial cells) have a generation time of about $28 \mathrm{~h}$. Nests of proliferating spermatogonia (both big and little interstitial cells) have generation times of 20-24 h. Spermatogonial proliferation is followed by a premeiotic $\mathrm{S}+\mathrm{G} 2$ phase, which lasts about $20 \mathrm{~h}$, and meiosis, which lasts about $22 \mathrm{~h}$. Postmeiotic differentiation of spermatids requires a variable period of 12 to $29 \mathrm{~h}$. Hence the entire spermatogenesis pathway requires about 5-7 days to complete.

\section{Quantitative estimate of cell flow through the spermatogenesis pathway}

Our results permit a direct estimate of the overall flow of cells through the spermatogenesis pathway. From the number of meiotic cells in testes $(6,100$; Fig. 4 and 5) and the turnover time of the meiotic population ( $22 \mathrm{~h}$; Fig. $6 \mathrm{~F})$, it is possible to calculate a flow rate of about 6,600 meiotic cells/day/testis. This corresponds to about 27,000 postmeiotic cells/day or about $1,100 \mathrm{sperm} / \mathrm{h}$. This value is in good agreement with direct measurements of sperm release from testes which yielded values of 700-1,200 sperm/testis/ h.

Calculation of the cell composition of testes based on the differentiation model in Fig. 8

It is possible to test the differentiation model in Fig. 8 quantitatively by comparing the observed numbers of each cell type in testes with the numbers expected based on the flow rate of cells through the pathway (see above) and the duration of the individual phases (Fig. 8). In order to make such a quantitative comparison, it is essential to define the 
Table 1. Comparison of numbers of big and little interstitial cells (spermatogonia), meiotic cells and postmeiotic cells with calculated values derived from different models of spermatogenesis

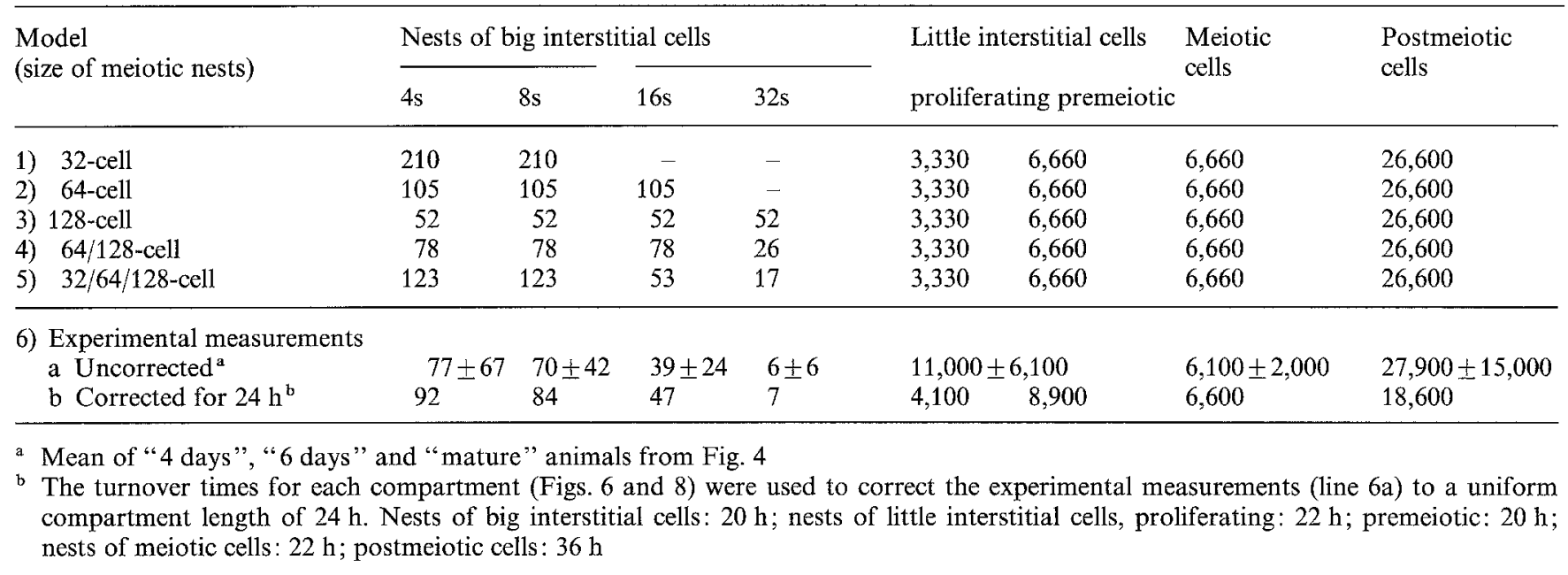

pathway more precisely than in Fig. 8. In particular it is necessary to specify the number of cell divisions stem cells undergo before meiosis. In principle this information could be obtained from the size distribution of meiotic nests. However, since such nests break during maceration (see Results), this size distribution is not useful. An alternative procedure is to match the observed distribution of big interstitial cell nests to the calculated distribution based on the differentiation model in Fig. 8 and different assumptions about the number of stem cell divisions prior to meiosis. The results of such calculations are shown in Table 1.

Assuming all stem cells undergo meiosis as nests of 32 cells, there will be equal numbers of nests of 4 and 8 big interstitial cell precursors (see Fig. 8). Table 1, line 1 indicates that for a flow rate of 6,700 meiotic cells per day, 210 nests of 4 and 8 big interstitial cell precursors are required. Similar calculations indicate that, respectively, 104 and 52 precursor nests will be required if meiosis occurs in nests of 64 or 128 cells (Table 1, lines 2 and 3). None of these models, however, appears to match the observed number of nests (Table 1 , line 6) very closely. In particular, the 32-cell model predicts numbers of $4 \mathrm{~s}$ and $8 \mathrm{~s}$ which are much higher than observed; it also includes no $16 \mathrm{~s}$ or $32 \mathrm{~s}$, which are clearly observed experimentally. Furthermore, the 64-cell model predicts more $8 \mathrm{~s}$ and $16 \mathrm{~s}$ than are observed, while the 128 -cell model predicts more $16 \mathrm{~s}$ and $32 \mathrm{~s}$ than are observed.

Although none of the simple models match the observed abundance and size distribution of big interstitial cells, it is possible to fit the experimental data with combinations of the three simple models. Two examples are shown in Table 1. Assuming half the meiotic cells occur in nests of 64 and half in nests of 128 gives the result shown in Table 1, line 4 . These calculated values match the observed numbers of $4 \mathrm{~s}$ and $8 \mathrm{~s}$ well (Table 1, line 6), but predict somewhat more $16 \mathrm{~s}$ and $32 \mathrm{~s}$ than are observed. An alternative possibility in which nests of 32,64 and 128 each contribute a third of all meiotic cells yields calculated numbers of big interstitial cell precursors which match the measured values for $16 \mathrm{~s}$ and $32 \mathrm{~s}$ more closely, but predict somewhat more $4 \mathrm{~s}$ and $8 \mathrm{~s}$ than are observed. In view of the potential errors in the experimental values due to breakage of nests, it does not appear fruitful to attempt a closer match to the experi- mental data. However, the generally good agreement between the calculations and experimental observations does suggest that the cell flow model in Fig. 8 is a good quantitative description of the spermatogenesis pathway. In particular, the calculations support the conclusion that stem cells undergo variable numbers of cell divisions prior to meiosis.

Table 1 also indicates that there is good agreement between the calculated numbers of little interstitial cells, meiotic cells and differentiating spermatids, and the experimentally observed abundance of these cells in testes. In particular, cells are not present in testes which the model does not account for nor are cells predicted on the basis of the model which are not present in testes. The calculations also support specific features of the cell flow model. For example, the round of cell division by little interstitial cells prior to premeiotic $S$ phase was included in the model based on the delay between the appearance of little interstitial cells and meiotic cells (Fig. 5). The existence of this proliferative step is supported by the quantitative calculations, since its elimination would significantly reduce the calculated numbers of little interstitial cells and increase the calculated numbers of big interstitial cells. Both changes would alter the good agreement between the model and experimental observations.

\section{Stem cell requirements in testes}

Table 1, line $6 \mathrm{a}$ indicates that a mature testis contains about 77 nests of four spermatogonia. Since the cell cycle of $4 \mathrm{~s}$ is about $20 \mathrm{~h}$, this corresponds to a flow rate of about 90 nests of 4 spermatogonia per day into the spermatogenesis pathway. These nests arise from nests of 2 spermatogonia, which are the direct product of stem cells. Assuming there is a constant steady state cell flow in the mature testis (no increase or decrease in testis size) then in each generation half of the stem cell population divides to yield further stem cells and half becomes committed to proliferation of nests of spermatogonia. Hence the size of the stem population in a testis is $2 \times$ flow rate (nests/day) $\times$ generation time of stem cells $(2 \times 90$ nests/day $\times 1.2$ days/generation $)$ or about 220 stem cells.

It is not possible to compare this number directly with $1 \mathrm{~s}+2 \mathrm{~s}$ in testes, since some $2 \mathrm{~s}$ are not stem cells but commit- 
ted precursors to $4 \mathrm{~s}$. However, the number of these committed $2 \mathrm{~s}$ can be calculated from the flow rate ( 90 nests/day) and the estimated cell generation time (1.2 days) to be about 110 nests or 220 cells per testis. Thus the sum of stem cells and committed $2 \mathrm{~s}$ yields a value of about $4401 \mathrm{~s}+2 \mathrm{~s}$ in mature testes. This value is in good agreement with measurements of $530 \pm 350 \mathrm{ls}+2 \mathrm{~s}$ in testes (data not shown).

From these results it is also possible to estimate the proportion of stem cells in a sexual animal involved in spermatogenesis. The sexual animals used in this study contained about $5,500 \pm 1,800$ total $1 \mathrm{~s}+2 \mathrm{~s}$. They usually had five to eight testes containing a total of about $2,200-3,5001 \mathrm{~s}+2 \mathrm{~s}$. Thus, while about half of all stem cells are occupied with spermatogenesis, there are still significant numbers of stem cells which can contribute to growth of the stem cell population, nematocyte differentiation and nerve differentiation. Indeed, $H$. carnea used in this study continue to produce nematocytes (Fig. 7) and to grow (i.e. bud) actively during periods of sexuality.

\section{Testis differentiation is a local event}

The above conclusions have several interesting implications. First, it is clear that the number of stem cells in a testis is sufficient to supply the stem cell requirements of active testes for spermatogenesis. There is no need to postulate migration of stem cells into testes from neighbouring regions outside the testis in order to support the high rate of spermatogenesis (27,000 sperm/day; Table 1$)$. Conversely, there does not appear to be an excess of stem cells in testes over and above the requirements for self-renewal and maintenance of spermatogenesis. In particular, there are not enough stem cells in testes to support extensive nematocyte differentiation in addition to spermatogenesis. This conclusion is in good agreement with histological observations of nematocyte differentiation in sexual animals (Fig. 7), which indicate that nests of differentiating nematocytes are not present in testes but are common in the surrounding gastric tissue.

The two observations above support the idea that testis differentiation is a local event in which stem cells within the region of the testis change their behaviour from that typical of gastric tissue (self-renewal leading to growth of the stem cell population and nematocyte differentiation) to that typical of testes (limited self-renewal, no nematocyte differentiation and extensive spermatogenesis). Since this change in behaviour is limited to stem cells in the region of the testis, it appears that localized signals control spermatogenesis. At present the nature of these signals is unknown.

Acknowledgements. The authors thank Drs. Tobias Schmidt and Thomas Holstein for helpful discussion and critical reading of the manuscript. This research was supported by the Deutsche Forschungsgemeinschaft (Da 163/1-1; Schm 510/4-1).

\section{References}

Bode HR, David CN (1978) Regulation of a multipotent stem cell, the interstitial cell of Hydra. Prog Biophys Mol Biol 33:189-206
Brauer A (1891) Über die Entwicklung von Hydra. .itschr Wiss Zool 52:169-216

Brien P (1961) Etude d'Hydra pirardi (nov spec). Origine et répartition des nématocytes. Gamétogenèse. Involution postgamétique. Evolution réversible des cellules interstitielles. Bull Biol France Belg 95:301-364

Brien P (1965) L'embryogenèse et la sénescence de l'Hydre d'eau douce (Hydra fusca (oligactis) Pallas). Académie royale de Belgique Mémoires Tome XXXVI fase 1

Brien P, Reniers-Decoen M (1950) Etude d'Hydra viridis (L). La blastogenèse, la spermatogenèse, l'ovogenèse. Ann Soc Roy Belg 81:33-110

Brien P, Reniers-Decoen M (1951) La gametogenèse et l'intersexualité chez Hydra attenuata [Pall]. Ann Soc Zool Belg 82:285-327

Brien P (1965) L'embryogenèse et la sénescence de l'Hydre d'eau douce (Hydra fusca (oligactis) Pallas). Académie royale de Belgique Mémoires Tome XXXVI fasc 1

Campbell RD, David CN (1974) Cell cycle kinetics and development of Hydra attenuata. II. Interstitial cells. J Cell Sci 349-358

Cowden RR, Curtis SK (1981) Microfluorometric investigations of chromatin structure. I. Evaluation of nine DNA-specific fluorochromes as probes of chromatin organisation. Histochemistry $72: 11-23$

David CN (1973) A quantitative method for maceration of Hydra tissue. Wilhelm Roux Arch 171:259-268

David CN, Campbell RD (1972) Cell cycle kinetics and development of Hydra attenuata. I. Epithelial cells. J Cell Sci 11:557-568

David CN, Challoner D (1974) Distribution of interstitial cells and differentiating nematocytes in nests in Hydra attenuata. Am Zool 14:537-542

David CN, Gierer G (1974) Cell cycle kinetics and development of Hydra attenuata. III. Nerve and nematocyte differentiation. J Cell Sci 16:359-375

Downing E (1905) The spermatogenesis of Hydra. Zool Jahrb Abt Anat Ontog 21:379-426

Hyman L (1931) Taxonomic studies on the Hydras of North America. III. Rediscovery of Hydra carnea L. Agassiz (1850) with a description of its characters. Trans Am Microsc Soc $50: 20-239$

Kleinenberg N (1872) Hydra. Eine anatomisch-entwicklungsgeschichtliche Untersuchung. Leipzig

Littlefield CL, Dunne JF, Bode RH (1985) Spermatogenesis in Hydra oligactis: I. Morphological description and characterisation using a monoclonal antibody specific for cells of the spermatogenic pathway [in press]

Loomis WF, Lenhoff HM (1956) Growth and sexual differentiation of hydra in mass culture. J Exp Zool 132:555-574

Romeis B (1968) Mikroskopische Technik. R Oldenburg Verlag, München Wien

Tardent P (1966) Zur Sexualbiologie von Hydra attenuata (Pall). Rev Suisse Zool 73:357-381

Tardent P (1978) Coelenterata, Cnidaria. In: Seidel F (1968) Morphogenese der Tiere Erste Reihe: Deskriptive Morphogenese. Lieferung 1:A-I. Gustav Fischer Verlag, Jena

Weismann A (1883) Die Entstehung der Sexualzellen bei den Hydromedusen. Gustav Fischer, Verlag, Jena

Zihler J (1972) Zur Gametogenese und Befruchtungsbiologie von Hydra. Wilhelm Roux's Arch 169:239-267

Received August 13, 1984

Accepted in revised form December 27, 1984 